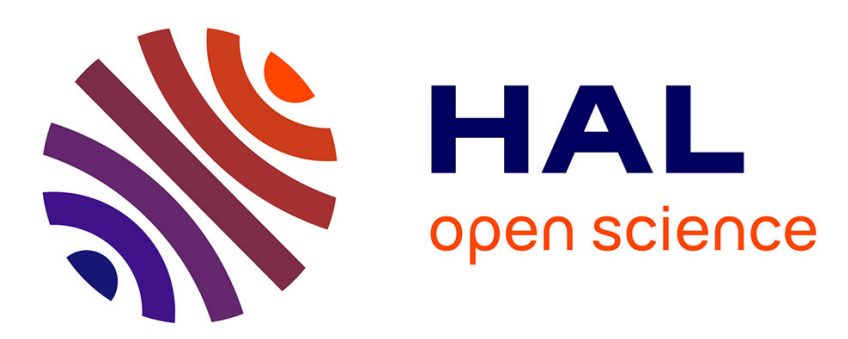

\title{
Molecular Dynamics Calculations of Anion Diffusion in Nitrogen-doped Yttria Stabilised Zirconia
}

\author{
Martin Kilo, Thorsten Homann, Thomas Bredow
}

\section{To cite this version:}

Martin Kilo, Thorsten Homann, Thomas Bredow. Molecular Dynamics Calculations of Anion Diffusion in Nitrogen-doped Yttria Stabilised Zirconia. Philosophical Magazine, 2006, 87 (06), pp.843-852. 10.1080/14786430600993349 . hal-00513775

\section{HAL Id: hal-00513775 \\ https://hal.science/hal-00513775}

Submitted on 1 Sep 2010

HAL is a multi-disciplinary open access archive for the deposit and dissemination of scientific research documents, whether they are published or not. The documents may come from teaching and research institutions in France or abroad, or from public or private research centers.
L'archive ouverte pluridisciplinaire HAL, est destinée au dépôt et à la diffusion de documents scientifiques de niveau recherche, publiés ou non, émanant des établissements d'enseignement et de recherche français ou étrangers, des laboratoires publics ou privés. 


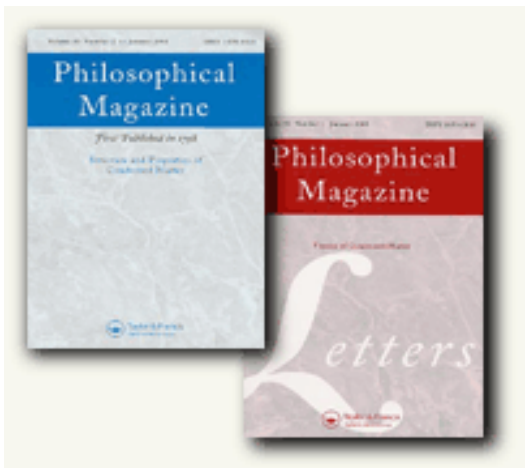

\section{Molecular Dynamics Calculations of Anion Diffusion in Nitrogen-doped Yttria Stabilised Zirconia}

\begin{tabular}{|c|c|}
\hline Journal: & Philosophical Magazine \& Philosophical Magazine Letters \\
\hline Manuscript ID: & TPHM-06-May-0183.R1 \\
\hline Journal Selection: & Philosophical Magazine \\
\hline $\begin{array}{r}\text { Date Submitted by the } \\
\text { Author: }\end{array}$ & 14-Aug-2006 \\
\hline Complete List of Authors: & $\begin{array}{l}\text { Kilo, Martin; TU Clausthal, IMET } \\
\text { Homann, Thorsten; Uni Hannover, Theoretische Chemie } \\
\text { Bredow, Thomas; Uni Hannover, Theoretische Chemie; Uni Bonn, } \\
\text { Theoretische Chemie }\end{array}$ \\
\hline Keywords: & diffusion, molecular dynamic simulations, point defects \\
\hline Keywords (user supplied): & zirconium oxynitride \\
\hline
\end{tabular}

\section{s) ScholaronE \\ Manuscript Central}




\title{
Molecular Dynamics Calculations of Anion Diffusion in Ni-
}

\section{trogen-doped Yttria Stabilised Zirconia}

\section{MARTIN KILO*†, THORSTEN HOMANN $\ddagger$, and THOMAS BREDOW $\$ \S$}

$\dagger$ TU Clausthal, Fakultät für Natur- und Materialwissenschaften, Robert-Koch-Str.

42, D-38678 Clausthal-Zellerfeld, Germany

† Universität Hannover, Lehrgebiet für Theoretische Chemie, Am Kleinen Felde 30, D-30167 Hannover, Germany

$\S$ Universität Bonn, Institut für Physikalische und Theoretische Chemie, Wegelerstr. 12, D-53115 Bonn, Germany

* Corresponding author, e-mail: martin.kilo@tu-clausthal.de

\begin{abstract}
Anion diffusion was simulated in the system $\left(\mathrm{Y}_{0.2} \mathrm{Zr}_{0.8}\right)-\left(\mathrm{O}_{1.72} \mathrm{~N}_{0.15}\right)$ with the molecular dynamics (MD) technique using the program DL_POLY, employing empirical potentials of the Buckingham type. To describe the nitrogen migration, nitrogen potentials had to be developed assuming the interaction of charged nitrogen shells with a mass of 0.15 amu with cores. Comparing experimental anion
\end{abstract}


diffusivities with the simulated ones, the diffusion coefficients were found to be of similar order. However, nitrogen diffuses five times slower than oxygen according to the computer simulation, while experimentally, the difference is reported to be smaller. Calculated activation enthalpies were 1.2 and $1.4 \mathrm{eV}$, respectively, for the two elements, with pre-exponential factors of $10^{-5}$ and $10^{-4} \mathrm{~cm}^{2} / \mathrm{s}$, respectively. 


\section{Introduction}

Although there are many materials which show high oxygen ion diffusion, there are no materials with high, and in particular predominant, nitrogen diffusivity. Nevertheless, finding such materials would make it possible to design new devices like direct nitrogen sensors, or to produce ammonia directly electrochemically.

One recent idea for producing such materials was the use of nitrogen-doped cation-stabilised zirconias. The base oxide, zirconia, can itself incorporate many lower-valent metal oxides; most prominent are yttria and calcia, while creating a large amount of oxygen vacancies, as shown by equation 1 .

$$
Y_{2} \mathrm{O}_{3}+2 \mathrm{Zr}_{Z r}^{x}+\mathrm{O}_{O}^{x} \rightarrow 2 Y_{Z r}^{\prime}+V_{O}^{2 \bullet}+2 \mathrm{ZrO}_{2}
$$

Incorporation of nitrogen should make it possible to further increase the amount of anion vacancies (equation 2). Since a $\mathrm{N}^{3-}$ anion is only $0.1 \AA$ larger than an $\mathrm{O}^{2-}$ anion, it can be assumed that the nitrogen diffusion in a (Me,Zr)-(N,O) system might be fast, like oxygen diffusion.

$$
\mathrm{N}_{2}+3 \mathrm{O}_{O}^{x} \rightarrow 2 \mathrm{~N}_{O}^{\prime}+V_{O}^{2 \bullet}+3 / 2 \mathrm{O}_{2}
$$

Nitrogen transport in oxynitrides itself has never been characterised by direct methods. There are only a few indirect investigations. Using qualitative estimates, Lerch [1] concluded from nitrogen uptake kinetics into pure zirconia that nitrogen diffusion might be slower than oxygen diffusion at $1400 \mathrm{~K}\left(\sim 10^{-9} \mathrm{~cm}^{2} / \mathrm{s}\right)$ by 3 orders of magnitude. Recently, Deghenghi et al. [2] and Chung et al. [3] investigated the reaction of polycrystalline tetragonal yttria stabilised zirconia (YSZ) containing 3 
mol\% yttria with nitrogen at elevated temperatures $\left(1400\right.$ to $\left.1600{ }^{\circ} \mathrm{C}\right)$. They used local Raman spectroscopy and transmission optical microscopy to investigate the migration of the moving reaction front for the formation of the oxynitrides in a pure nitrogen atmosphere. Assuming the uptake reaction to be limited by the diffusion of nitrogen in the growing oxynitride layer, the two groups found activation enthalpies of $1.76 \mathrm{eV}$ [2] and $1.92 \mathrm{eV}$ [3] for nitrogen diffusion, with preexponential factors of $3.98 \times 10^{-3} \mathrm{~cm}^{2} / \mathrm{s}[2]$, and $7.5 \times 10^{-2} \mathrm{~cm}^{2} / \mathrm{s}$ [3], respectively. Only very recently, nitrogen diffusion [4] as well as oxygen diffusion [5] was investigated by direct methods. Surprisingly, it seems that oxygen and nitrogen diffusion have different activation enthalpies, about $1 \mathrm{eV}$ for oxygen transport [5] and $2.2 \mathrm{eV}$ for nitrogen transport [4]. This observation is in line with results of diffuse neutron scattering experiments, where almost the same activation enthalpies $(0.9 \mathrm{eV}$ for oxygen transport and $2.0 \mathrm{eV}$ for nitrogen diffusion) were observed [6]. However, results of direct measurements of ionic conductivity are contradictory, giving activation enthalpies between 1 and 2 $\mathrm{eV}$, and conductivities that are not constant as a function of time [7]. This is mainly due to the fact that until now, conductivity experiments were performed only in air, while it is known that zirconium oxynitrides are not stable with respect to oxygen at enhanced temperatures and can decompose quickly by releasing nitrogen [1].

It is the goal of this paper to compare these experimental results by modelling the anion diffusion in the $\mathrm{Y}-\mathrm{Zr}-\mathrm{O}-\mathrm{N}$ system using molecular dynamics (MD) techniques. As a preliminary step, it was necessary to develop empirical potential sets to model nitrogen interactions with oxygen and transition metal cations. 


\section{Computer simulation}

Molecular dynamics calculations were performed using the program DL_POLY [8]. Cubic supercells with $20 \mathrm{~mol} \%$ yttrium (in the cationic sublattice) and $6 \mathrm{~mol} \%$ nitrogen (in the anionic sublattice) were set up by randomly placing cations, oxygen vacancies and nitrogen anions on an initially perfect cubic $\mathrm{ZrO}_{2}$ lattice. Each of the up to ten supercells considered consisted of $256 \mathrm{ZrO}_{2}$ units. The yttrium and nitrogen dopant concentrations were chosen to be similar to the experimental sample compositions [4].

There are currently no potentials available for describing metal-nitrogen interactions. Therefore, it was necessary to develop appropriate potentials by fitting to the experimental properties of the doped zirconium oxynitride using the program GULP [9]. Potentials of the Buckingham type supplemented by electrostatic terms [10], equation 3, were used:

$$
V\left(r_{i j}\right)=A \exp \left(-\frac{r_{i j}}{\rho}\right)-\frac{C}{r_{i j}{ }^{6}}+\frac{q_{i} q_{j}}{r_{i j}}
$$

Here, $\mathrm{A}, \rho$ and $\mathrm{C}$ are parameters which were fitted to the experimental properties of the material, $q_{j}$ are the charges and $r_{i j}$ are the distances between two atoms $\mathrm{i}$ and $\mathrm{j}$. $A$ is a measure for the interaction strength, $\rho$ measures the distance over which the attractive force decrease, and $\mathrm{C}$ is a measure for the repulsive force. These potentials were supplemented by harmonic potentials (equation 4) for the anions, where it is assumed that an atom consists of a core and a mass-less shell coupled by a harmonic spring. In equation 4, the only free parameter is the spring constant $k$, and $\mathrm{r}_{\mathrm{i}}$ is the 
radius between core and shell of the atom i. Further parameters are the charge, which can be arbitrarily distributed between core and shell, while the full charge has to be equal to the formal charge.

$$
V\left(r_{i}\right)=\frac{1}{2} \cdot k \cdot r_{i}^{2}
$$

In the case of molecular dynamics, a small mass has to be attributed to the shell, since if the shell was mass free; it would not be possible to calculate its kinetic energy [10]. For static lattice calculations, the mass of the shell is 0 .

After getting the potential parameters, molecular dynamics runs were performed in the temperature range from 1000 to $3000 \mathrm{~K}$, and anion diffusion coefficients were obtained from the trajectories of the respective anions. Radial distribution functions, lattice constants and other parameters were obtained as well.

\section{Results and discussion}

\subsection{Nitrogen potentials}

In order to get metal-nitrogen potential parameters, we started with the wellestablished parameter sets developed by Catlow et al [11] for metal-oxygen interactions. In contrast to the well-known metal-oxygen potentials, there are only a few parameter sets available to describe metal-nitrogen or oxygen-nitrogen interactions. Furthermore, pure (oxygen-free) metal nitrides are much more covalent than oxides or the oxynitrides investigated here.

Therefore, a parameter set was developed for $\mathrm{Y}-\mathrm{N}, \mathrm{Zr}-\mathrm{N}$ and $\mathrm{O}-\mathrm{N}$ using static 
lattice calculations using the program GULP [9]. Here, we fixed the oxygen potential parameters to the values given by Catlow et al. [11] and fitted the nitrogen potential parameters using the experimental lattice parameters for $\mathrm{YZrON}$. As mentioned above, for MD calculations the shell of the anions, originally assumed to be massless in the static-lattice calculations, had to be given a small mass $(1 \%$ of the whole mass of the element).

The parameters obtained are summarised in Table 1 and Table 2.

[Insert Table 1 here]

[Insert Table 2 here]

\subsection{Molecular dynamics runs}

In order to perform the MD runs, systems were constructed initially where both the cations $(\mathrm{Y} / \mathrm{Zr})$ as well as the anions $\left(\mathrm{O} / \mathrm{N} / \mathrm{V}_{\mathrm{O}}{ }^{2 \cdot}\right)$ were randomly placed on the respective sublattices. For cation doping, we chose $10 \mathrm{~mol} \% \mathrm{Y}_{2} \mathrm{O}_{3}$ and $90 \mathrm{~mol} \%$ $\mathrm{ZrO}_{2}$, corresponding to $20 \mathrm{~mol} \% \mathrm{Y}$ on the cation sublattice. For nitrogen doping, two relatively high nitrogen contents, 6 and $10 \mathrm{~mol} \%$, on the anion sublattice were chosen, in order for the effect of the nitrogen to be well-distinguished. These systems correspond to the stoichiometry of the experimental systems [4], and for each system, 5 different random configurations were initially set up.

$4 \times 4 \times 4$ boxes each containing 256 cations and the corresponding number of anions were constructed. Calculation times were up to $0.1 \mathrm{~ns}$ (including 10 ps equilibration) 
in the temperature range from 1000 to $2500 \mathrm{~K}$, with a small time step of 0.05 fs. All calculations were performed under $n p T$ conditions (npt: particle number $n$, pressure $p$ and temperature $\mathrm{T}$ kept constant).

As a first result, Figure 1 shows the lattice parameters obtained as a function of the temperature in comparison with the literature values taken from [6]. The lattice constants as well as the thermal expansion are in good agreement with experimental values [6], the calculated values are slightly higher than the (extrapolated) experimental data, but the difference is less than $1 \%$.

\section{[Insert Figure 1 here]}

Anion trajectories were in all cases along the [100] direction, both for the oxygen and the nitrogen diffusion; there is no evidence for anion transport along [110] or [111]. Furthermore, the trajectories are linear; no curvature was observed. This is despite the fact that during the linear jumps the anions came close to the cations at the midpoint of the migration pathway (see Figure 2).

\section{[Insert Figure 2 here]}

Furthermore, the radial distribution functions, defined as

$$
g(r)=\frac{1}{N} \sum_{i=1}^{N} \sum_{j \neq i}^{N} \delta\left(r-r_{i j}\right)
$$

were calculated for the distribution of the three elements around oxygen and are shown in Figure 3. 
[Insert Figure 3 here]

Finally, the mean square displacements msd, defined as

$$
m s d=\left\langle r_{i}^{2}(t)\right\rangle=\frac{1}{N} \sum_{i=1}^{N}\left[r_{i}(t)-r_{i}(0)\right]^{2}=6 D t+B_{i}
$$

were calculated for the anions as a function of time. A typical plot is shown in Figure 4. From the slope, the oxygen diffusion coefficient was evaluated, with $B_{i}$ being the thermal factor arising from thermal vibrations. Reliable values of the slope were only obtained at temperatures above $600-800 \mathrm{~K}$. For too long times, the curve was not linear since there were considerable jumps across the corners of the simulation box. Therefore, the linear fit was performed on the early part of the plot.

\section{[Insert Figure 4 here]}

The calculated lattice properties of the zirconium oxynitride are qualitatively in agreement with the experimental data (Figure 1). This suggests that the potentials used describe the oxynitride reasonably accurately. The calculated thermal lattice expansion coefficient is $8 \times 10^{-6} \mathrm{~K}^{-1}$, which also compares well with the experimental value [11].

The pair distribution functions show that the distance between $\mathrm{O}$ and $\mathrm{O}$ is about $0.2 \AA$ smaller than between $\mathrm{N}$ and $\mathrm{O}$ and $0.4 \AA$ smaller than between $\mathrm{N}$ and $\mathrm{N}$ (first peak in Figure 3). Increasing the temperature significantly affects the anion-anion distances: there are several well-defined bands at $600 \mathrm{~K}$ forming a broad, nearly continuous band at $1900 \mathrm{~K}$. This reflects the fact that there is a very high disorder, 
due to the high amount of yttrium and nitrogen ions. This effect was also observed by Li [12] in YSZ. Radial distribution functions did show that the distance between cations and nitrogen anions on the one hand and between cations and oxygen anions on the other hand are practically identical. The $\mathrm{Y}^{3+}$-anion distance is $0.25 \AA$ higher than the $\mathrm{Zr}^{4+}$-anion distance. The minimum N-N distance is higher than the minimum O-N and O-O distance, respectively; the latter two are very similar (see Figure 3).

It is also observed that the nitrogen anion is more likely to be close to yttrium, while oxygen prefers to be close to zirconium cations. This is in contrast to the formal defect chemistry equation 7 :

$$
Y_{Z r}^{\prime}+N_{O}^{\prime} \rightarrow\left[Y_{Z r}^{\prime}+N_{O}^{\prime}\right]^{2^{\prime}}
$$

A reaction between nitrogen anion and stabiliser cation would formally lead to a doubly charged species, but can be rationalised by ionic size effects $\left(\mathrm{Y}^{3+}\right.$ is $0.2 \AA$ bigger than $\mathrm{Zr}^{4+}$ ), $\mathrm{N}^{3-}$ is $0.1 \AA$ bigger than $\mathrm{O}^{2-}$ ).

The mean square displacements of the anions show an almost linear time dependence making it possible to extract diffusion coefficients of the slope according to equation (6). The cations did not change place during the calculations but remained in their place, even above $2000 \mathrm{~K}$. This confirms the very low cation diffusion in this system, which is expected to be similar to that of YSZ [13].

\subsection{Comparison with literature}

Anion diffusivities calculated using molecular dynamics are shown in Figure 5. It 
can be seen that for all temperatures, the nitrogen diffusion is lower than the oxygen diffusion. At low temperatures, the diffusion coefficients were evaluated to be too high, as stated above.

\section{[Insert Figure 5 here]}

The activation enthalpy is 1.2 and $1.4 \mathrm{eV}$, respectively, for the two anions, much smaller than experimentally observed for nitrogen diffusion $(2 \mathrm{eV},[4])$ but greater than found for oxygen in $\mathrm{Y}_{0.2} \mathrm{Zr}_{0.8} \mathrm{O}_{1.72} \mathrm{~N}_{0.15}$ experimentally [5]. Nevertheless, the diffusion coefficients themselves agree within less than two orders of magnitude with the (extrapolated) experimentally determined diffusion coefficients. Furthermore, the calculated oxygen diffusivities are smaller than the oxygen diffusivities in pure YSZ [14], see also Figure 5. This is in agreement with the experimental findings. There are some investigations on the conductivity in the YZrON system [15]. Wendel et al. observed that the conductivity in $\mathrm{YZrON}$ is higher, but also with a higher slope, than in the base YSZ material. Their activation enthalpies are 1.1 to $1.2 \mathrm{eV}$, depending on the nitrogen content. This matches very well the here observed activation enthalpies for anion diffusion. So we conclude, that the potentials derived here describe ionic oxynitrides accurately.

\section{Conclusion}

For the first time, empirical potentials for ionic oxynitrides were developed. Using these parameters, nitrogen and oxygen diffusivities were calculated for $\mathrm{Y}_{0.2} \mathrm{Zr}_{0.8} \mathrm{O}_{1.72} \mathrm{~N}_{0.15}$ using molecular dynamics. The nitrogen diffusion is five times 
slower than the oxygen diffusion, with similar activation enthalpies for the two anions. The preexponential factors of diffusion are in the range $10^{-4}$ to $10^{-5} \mathrm{~cm}^{2} / \mathrm{s}$.

\section{Acknowledgements}

Financial support by the DFG in the framework of its priority program SPP 1136 is gratefully acknowledged. R.A.J. is thanked for proofreading.

\section{References}

[1] M. Lerch, J. Lerch, K. Lerch, J. Mater. Sci. Lett. 152127 (1996)

[2] G. Deghenghi, T.-J. Chung, V. Sergo, J. Am. Ceram. Soc. 86169 (2003)

[3] T.-J. Chung, J.-S. Lee, D.-Y. Kim, H. Song, J. Am. Ceram. Soc. 823193 (1999)

[4] M. Kilo, M.A. Taylor, C. Argirusis, G. Borchardt, M. Lerch, O. Kaïtasov, B. Lesage, Phys. Chem. - Chem. Phys. 63645 (2004)

[5] M. Kilo, M.A. Taylor, G. Borchardt, I. Kaiser-Bischoff, G. Boysen, M. Lerch, Solid State Ionics, submitted.

[6] I. Kaiser-Bischoff, G. Boysen, C. Scherf, T. Hansen, Phys -Chem. - Chem. Phys. 72061 (2005)

[7] I. Valov, J. Janek, to be submitted

[8] DL_POLY is a package of molecular simulation routines written by W. Smith and T.R. Forester, copyright The Council for the Central Laboratory of the Research Councils, Daresbury Laboratory at Daresbury, Nr. Warrington (1996).

[9] J.D. Gale, J. Chem. Soc. Faraday Trans. 93629 (1997)

[10] C.R.A. Catlow, Computer Modelling in Inorganic Crystallography, Academic Press, London 1997.

[11] G.V. Lewis, C.R.A. Catlow, J. Phys. C: Solid State Phys. 181149 (1985)

[12]X. Li, B. Hafskjold, J. Phys.: Condens. Matter 71255 (1995)

[13]M. Kilo, G. Borchardt, B. Lesage, O. Kaïtasov, S. Weber, S. Scherrer, J. Europ.Ceram. Soc. 202069 (2000)

[14] M. Kilo, C. Argirusis, G. Borchardt, R.A. Jackson, Phys. Chem. - Chem. Phys. 5 2219 (2003)

[15] J. Wendel, M. Lerch, W. Laqua, J. Solid State Chem. 142163 (1999). 


\section{Tables}

\begin{tabular}{|l|c|c|c|l|}
\hline Buckingham & $\mathrm{A} / \mathrm{eV}$ & $\rho / \AA$ & $\mathrm{C} / \mathrm{eV} \AA^{6}$ & Reference \\
\hline $\mathrm{Y}-\mathrm{O}_{\text {shell }}$ & 1766.4 & 0.3385 & 0.0 & {$[14]$} \\
\hline $\mathrm{Zr}-\mathrm{O}_{\text {shell }}$ & 1024.6 & 0.3760 & 0.0 & {$[14]$} \\
\hline $\mathrm{O}_{\text {shell }}-\mathrm{O}_{\text {shell }}$ & 22764.0 & 0.1490 & 27.9 & {$[14]$} \\
\hline $\mathrm{O}_{\text {shell }}-\mathrm{N}_{\text {shell }}$ & 12134.0 & 0.2606 & 133.0 & This paper \\
\hline $\mathrm{N}_{\text {shell }}-\mathrm{N}_{\text {shell }}$ & 10282.4 & 0.3293 & 234.0 & This paper \\
\hline $\mathrm{Y}-\mathrm{N}_{\text {shell }}$ & 2500.2 & 0.3535 & 43.3 & This paper \\
\hline $\mathrm{Zr}-\mathrm{N}_{\text {shell }}$ & 1612.2 & 0.3935 & 43.3 & This paper \\
\hline
\end{tabular}

Table 1: Buckingham parameters used for the molecular dynamics calculations

\begin{tabular}{|l|l|l|l|l|l|l|}
\hline Spring & $\mathrm{k} / \mathrm{eV} \AA^{-2}$ & $\mathrm{q}_{\text {core }} /|\mathrm{e}|$ & $\mathrm{q}_{\text {shell }} /|\mathrm{e}|$ & $\mathrm{m}_{\text {core }} / \mathrm{amu}$ & $\mathrm{m}_{\text {shell }} / \mathrm{amu}$ & Reference \\
\hline $\mathrm{O}_{\text {core }}-\mathrm{O}_{\text {shell }}$ & 27.29 & 0.53 & -2.53 & 15.85 & 0.15 & {$[14]$} \\
\hline $\mathrm{N}_{\text {core }}-\mathrm{N}_{\text {shell }}$ & 24.85 & 0.95 & -3.95 & 13.85 & 0.15 & This paper \\
\hline
\end{tabular}

Table 2: Harmonic potential parameters used here

Table 3: Compilation of calculated and extrapolated experimental diffusion coefficients. Experimental diffusion coefficients were measures in the temperature region of 400 to $1200 \mathrm{~K}(\mathrm{~N})$ and 400 to $1000 \mathrm{~K}(\mathrm{O})$. The results of the respective Arrhenius fits are: $\mathrm{D}(\mathrm{N}, \exp )=0.8 * \exp (-2.2 \mathrm{eV} / \mathrm{kT}) \mathrm{cm}^{2} / \mathrm{s}$ [3] and $\mathrm{D}(\mathrm{O}, \exp )=10^{-}$ $7 * \exp (-0.95 \mathrm{eV} / \mathrm{kT})[5]$.

\begin{tabular}{|c|c|c|c|c|}
\hline $\mathrm{T}$ & $\mathrm{D}(\mathrm{O}, \mathrm{MD})$ & $\mathrm{D}(\mathrm{N}, \mathrm{MD})$ & $\mathrm{D}(\mathrm{O}, \exp )$ & $\mathrm{D}(\mathrm{N}, \exp )$ \\
\hline $\mathrm{K}$ & $\mathrm{m}^{2} / \mathrm{s}$ & $\mathrm{m}^{2} / \mathrm{s}$ & $\mathrm{m}^{2} / \mathrm{s}$ & $\mathrm{m}^{2} / \mathrm{s}$ \\
\hline 1100 & $4 * 10^{-13}$ & - & $1 * 10^{-12}$ & $1.9^{*} 10^{-14}$ \\
\hline 1200 & $2.3^{*} 10^{-13}$ & - & $2.3^{*} 10^{-11}$ & $1.2 * 10^{-13}$ \\
\hline 1300 & $5^{*} 10^{-13}$ & - & $5 * 10^{-11}$ & $6^{*} 10^{-13}$ \\
\hline 1400 & $6^{*} 10^{-14}$ & $4 * 10^{-14}$ & $9^{*} 10^{-11}$ & $2.2^{*} 10^{-12}$ \\
\hline 1500 & $1.7 * 10^{-13}$ & $1.3 * 10^{-15}$ & $1.6^{*} 10^{-10}$ & $7 * 10^{-12}$ \\
\hline 1600 & $4.4^{*} 10^{-13}$ & $6^{*} 10^{-13}$ & $2.5^{*} 10^{-10}$ & $1.9^{*} 10^{-11}$ \\
\hline 1800 & $1.5^{*} 10^{-12}$ & $7^{*} 10^{-13}$ & $6^{*} 10^{-10}$ & $1.1 * 10^{-10}$ \\
\hline 2000 & $3 * 10^{-12}$ & $2.7 * 10^{-12}$ & $1.1 * 10^{-9}$ & $4.1 * 10^{-10}$ \\
\hline 2500 & $1.1 * 10^{-11}$ & $1.1 * 10^{-11}$ & $2.8^{*} 10^{-9}$ & $4.6 * 10^{-9}$ \\
\hline
\end{tabular}




\section{Figures}

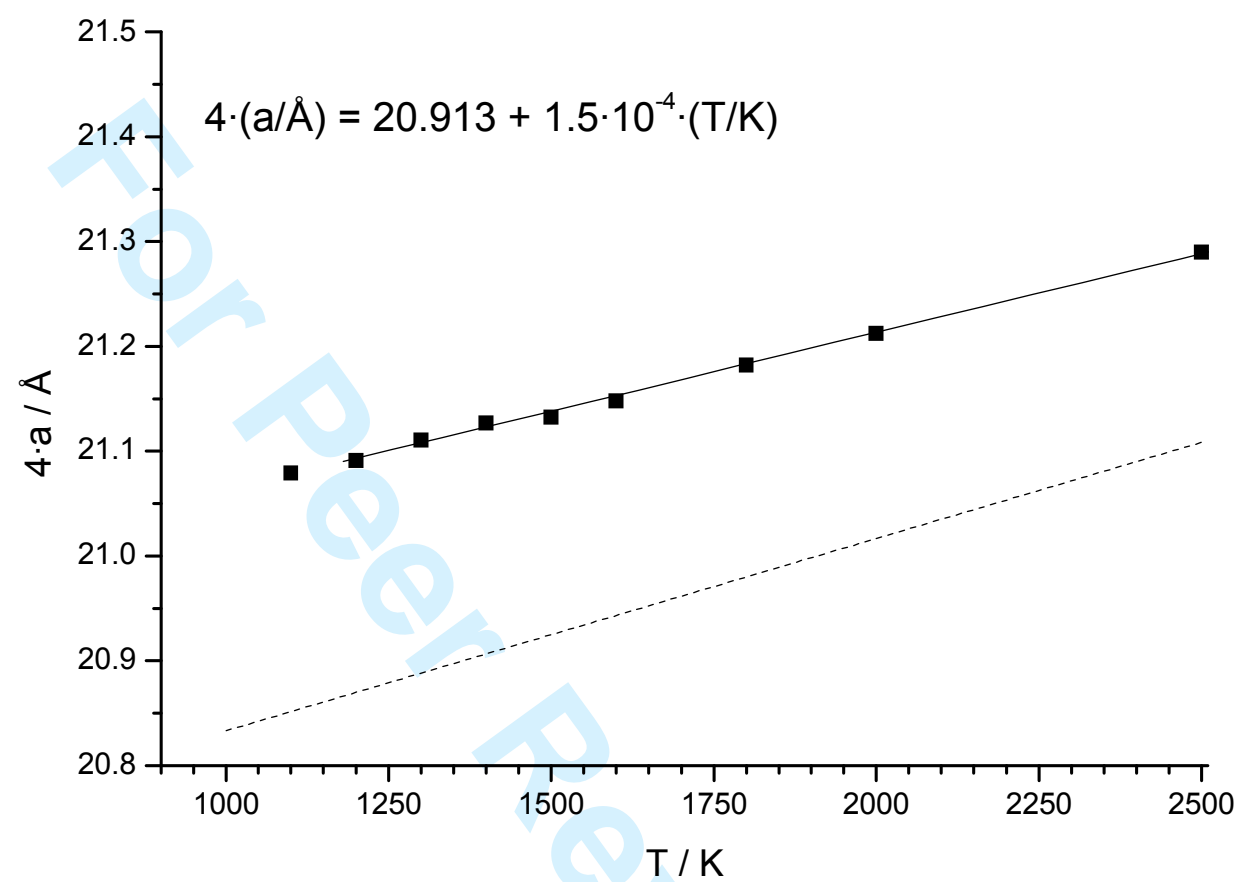

Figure 1: Lattice expansion for $\mathrm{Y}_{0.2} \mathrm{Zr}_{0.8} \mathrm{O}_{1.72} \mathrm{~N}_{0.15}$ as calculated using molecular dynamics. Dashed line: Extrapolated experimental values, taken from [6]. 


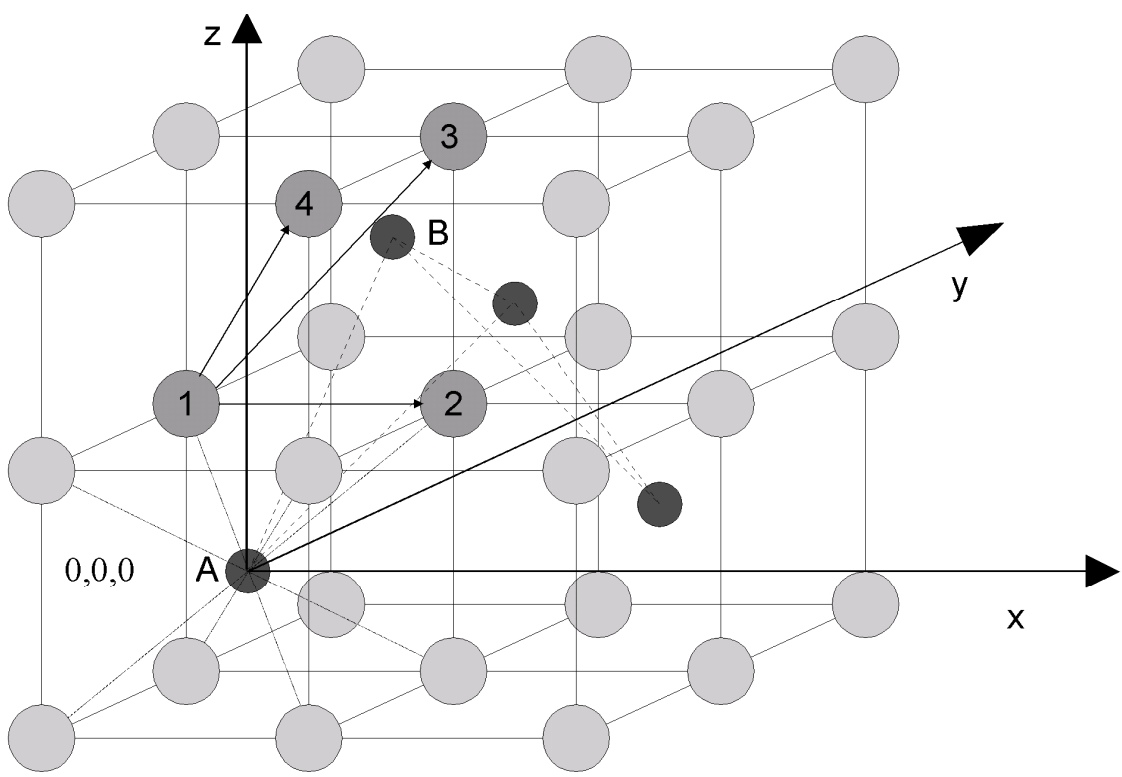

Figure 2: Sketch of the Fluorite lattice and of possible pathways for migrating anions. Cations: black small circles; anions: big grey circles. From the starting point marked 1 , an anion jumping to point 2 is migrating in the [100] direction, a 1-3 jump is in the [110] direction and a 1-4 jump is in [111] direction. During a [100] jump, the cations at $\mathrm{A}$ and $\mathrm{B}$ are closest neighbours. 


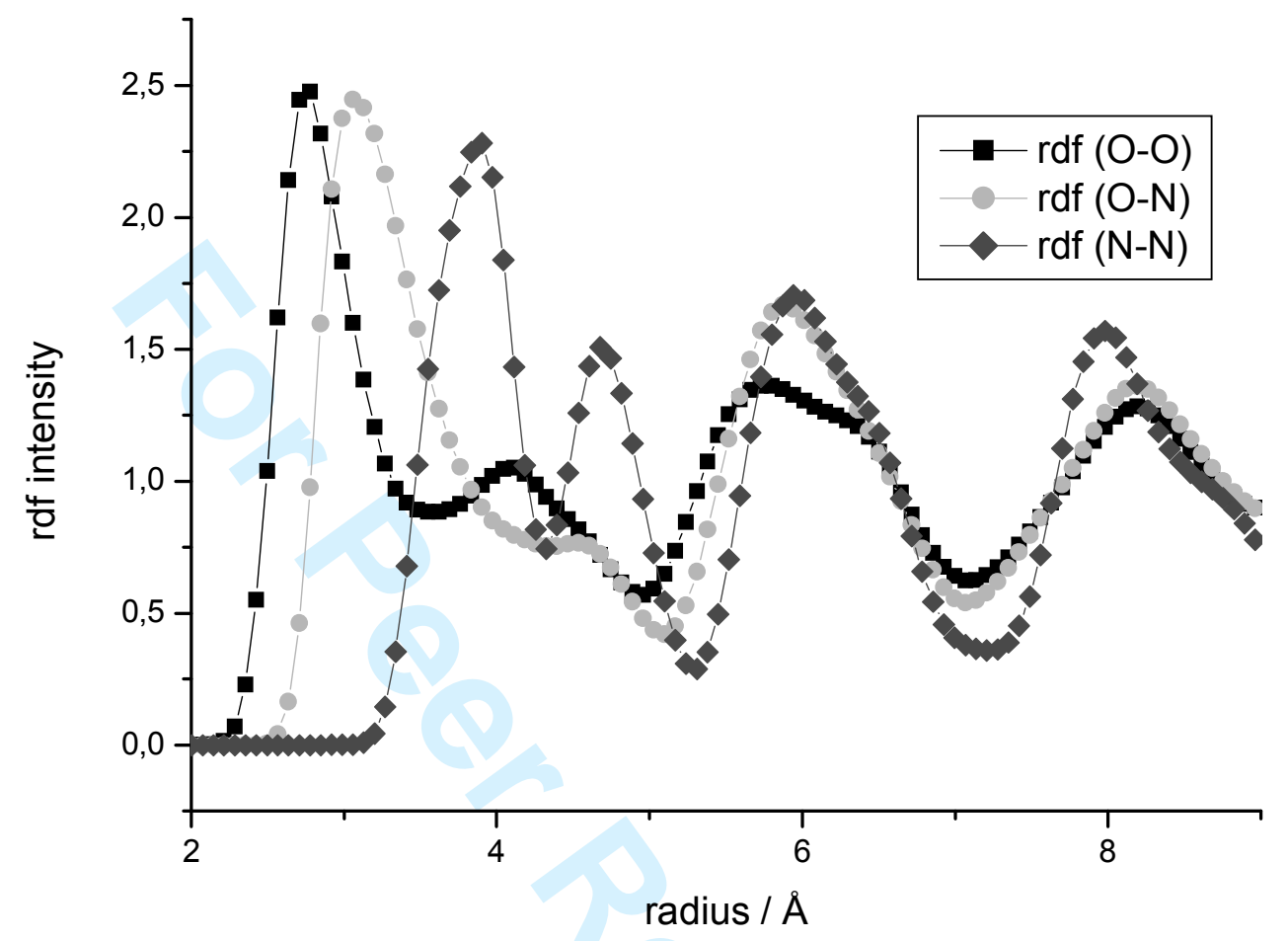

Figure 3: Radial distribution function for anions at $1000 \mathrm{~K}$. 


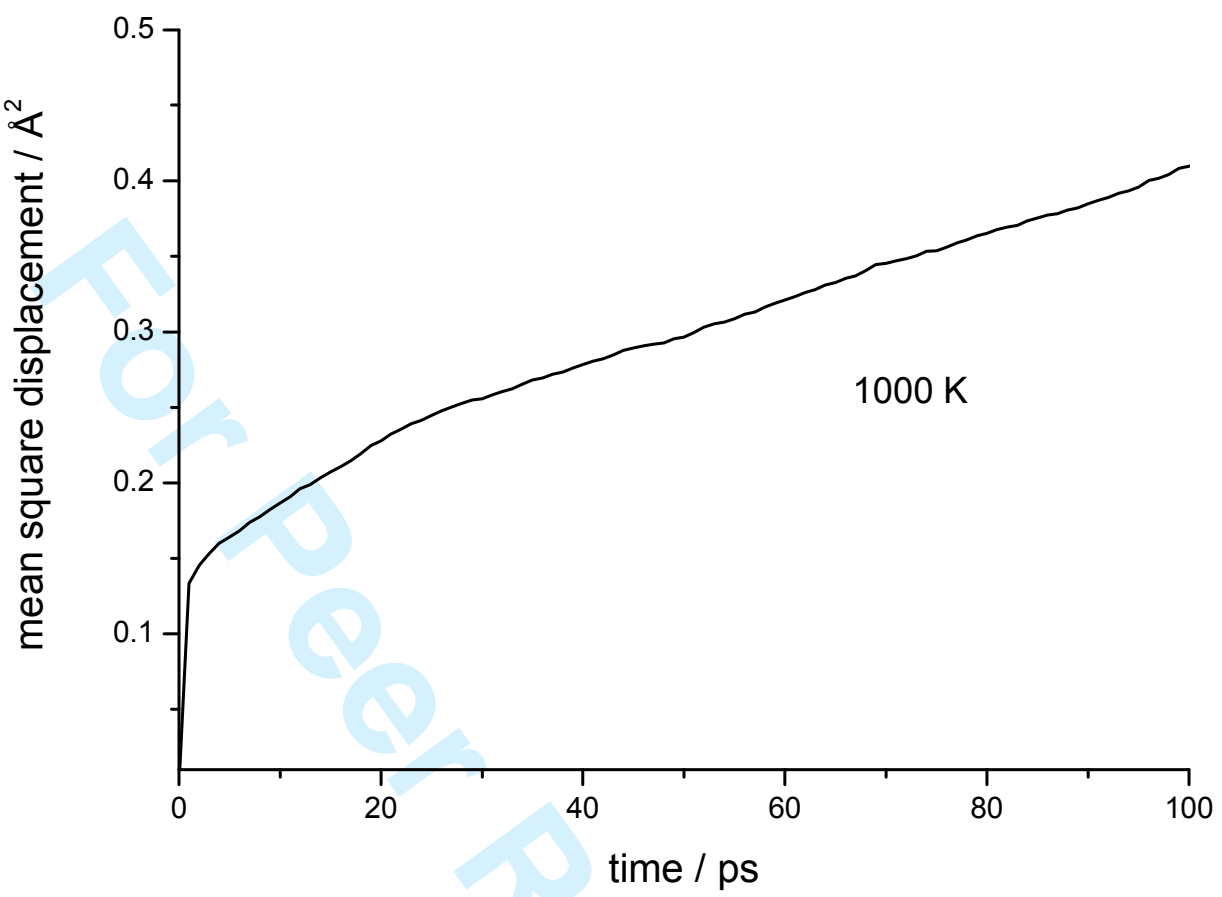

Figure 4: Mean square displacement of oxygen at $1000 \mathrm{~K}$. 


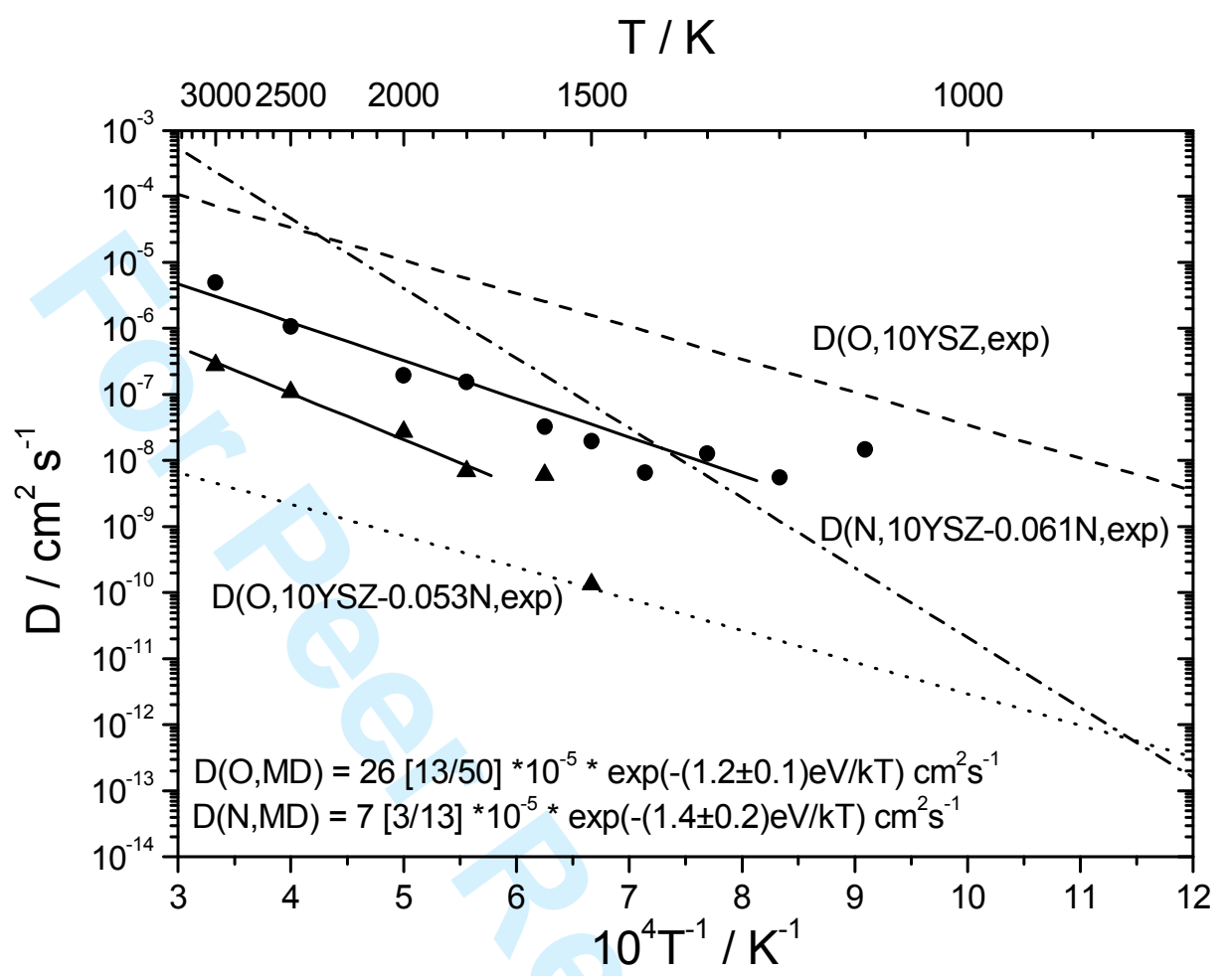

Figure 5: Anion diffusion in $\mathrm{Y}_{0.2} \mathrm{Zr}_{0.8} \mathrm{O}_{1.72} \mathrm{~N}_{0.15}$. Triangles Calculated nitrogen diffusion coefficients; Circles: Calculated oxygen diffusion coefficients. Straight lines: Fits of the respective calculated diffusion coefficients. Also shown are experimental and calculated values for anion diffusivities in this material (dotted [O] and dash dotted [N] lines; taken from [5] and [6]), as well as the oxygen diffusivity in $\mathrm{Y}_{0.2} \mathrm{Zr}_{0.8} \mathrm{O}_{1.9}$ (10YSZ), (dashed line, taken from [14]). 